\title{
A CURRICULARIZAÇÃO DA EXTENSÃO: ANÁLISE DE UMA EXPERIÊNCIA NO CURSO SUPERIOR DE TECNOLOGIA EM DESIGN DE MODA
}

\author{
Letícia Cunico ${ }^{\text {D } 1}$ e Marizete Bortolanza Spessatto iD2
}

\section{Resumo}

A estratégia 12.7 do Plano Nacional de Educação (2014-2024), a Resolução CNE/CES no 7, de 2018 e a Resolução no 40 de 2016 CONSUP/IFSC tratam da inclusão de $10 \%$ da carga horária em extensão nos currículos dos cursos superiores, materializando a indissociabilidade do ensino, pesquisa e extensão. Considerando essas normativas, busca-se neste trabalho analisar uma experiência desenvolvida em uma unidade curricular do curso Superior de Tecnologia em Design de Moda do IFSC- Araranguá, a fim de contribuir com uma proposta de curricularização da extensão. Trata-se de uma pesquisa de abordagem qualitativa, com coleta de dados por meio de pesquisa-ação. Os resultados do trabalho e as vozes dos estudantes ouvidos sinalizam para a importância do tripé ensino, pesquisa e extensão para a formação profissional e cidadã dos sujeitos que passam pela educação superior.

Palavras-chave: Curricularização da extensão; Educação Profissional e Tecnológica; Design de Moda.

\section{EXTENSION CURRICULARIZATION: ANALYSIS OF AN EXPERIENCE IN THE SUPERIOR FASHION DESIGN TECHNOLOGY COURSE}

\begin{abstract}
Strategy 12.7 of the National Education Plan (2014-2024), CNE / CES Resolution No. 7, of 2018 and Resolution No. 40 of 2016 CONSUP / IFSC deal with the inclusion of $10 \%$ of the workload in extension in the curricula of higher education courses, materializing the inseparability of teaching, research and extension. Request these regulations, this work seeks to analyze an experience developed in a curricular unit of the Higher Technology in Fashion Design course at IFSCAraranguá, in order to contribute with a proposal for the extension curriculum. This is a qualitative approach research, with data collection through action research. The results of the work and the voices of the students heard point to the importance of the teaching, research and extension tripod for professional and citizen training, subjects who undergo higher education.
\end{abstract}

Keywords: Extension curriculum; Professional and Technological Education; Fashion design.

\footnotetext{
${ }^{1}$ Doutoranda em Engenharia e Gestão do Conhecimento pela Universidade Federal de Santa Catarina (UFSC). Mestra em Administração (UFSC). Afiliação institucional: Instituto Federal de Educação, Ciência e Tecnologia de Santa Catarina (IFSC).

${ }^{2}$ Doutora em Educação pela Universidade Federal de Santa Catarina (UFSC). Afiliação institucional: Instituto Federal de Educação, Ciência e Tecnologia de Santa Catarina (IFSC).
}

Perspectivas em Diálogo, Naviraí, v. 09, n. 19, p. 282-300, jan./abr. 2022. 


\section{Introdução}

Segundo estudos da empresa especializada em pesquisas de mercado IEMI (2020), o consumo de produtos no varejo de vestuário no Brasil em 2019 foi de $\mathrm{R} \$ 231,3$ bilhões, representando uma média per capita ano de $\mathrm{R} \$$ $1.100,00$, sendo 6,3 bilhões de peças comercializadas. Vale destacar, nesse cenário, uma taxa de crescimento nominal de $30 \%$ no e-commerce Business-toconsumer (B2C) ${ }^{1}$, em uma média de $\mathrm{R} \$ 169,00$ por compra e 6 milhões de compradores. São um total de 2,6 mil unidades produtivas no Brasil, gerando 258 mil empregos diretos ou indiretos. Considerando os efeitos da pandemia de covid-19, a partir de 2020, os resultados preliminares apresentam queda de $21 \%$ do volume de peças comercializadas no varejo de vestuário, assim como queda de $22,3 \%$ da produção (IEMI, 2020).

Nesse contexto de indústria, a região Sul do estado de Santa Catarina, destaca-se como polo industrial têxtil e de confecção, contribuindo de forma significativa com o desenvolvimento do setor no estado. Segundo os dados da Federação das Indústrias do Estado de Santa Catarina - FIESC (2019), o estado contava, em 2019, com 9.104 empresas no ramo têxtil, confecção, couro e calçados, entre micro, pequenas, médias e grandes empresas, com mais de 170 mil trabalhadores. Em Santa Catarina, o setor contribui com 17,99\% da participação de indústrias do estado e reúne o segundo maior polo industrial do Brasil. Em Araranguá, uma das principais cidades da região, no grupo de confecção de artigos do vestuário e acessórios, o número de empresas é 105 e o número de empregos é de 755 , segundo os últimos dados divulgados, datados de 2019 (FIESC, 2019).

Quando da expansão da Rede Federal de Educação Profissional e Tecnológica, projeto implementado nacionalmente a partir de 2008, definiu-se que os institutos federais de educação deveriam, na criação de seus cursos, atender às demandas nas regiões nas quais foram estabelecidos. Por isso, no câmpus Araranguá, do Instituto Federal de Educação, Ciência e Tecnologia de Santa Catarina-IFSC, foi criado o curso superior de Tecnologia em Design de Moda. O Projeto Pedagógico é datado de agosto de 2014 e, segundo a Portaria da Direção-Geral do Câmpus Araranguá No 44 de 2021, encontra-se em processo de revisão, suscitando uma reflexão sobre formas de proporcionar experiências significativas à trilha formativa dos futuros egressos. Esses sujeitos têm experiências sociais e saberes que são diversos e precisam ser ouvidos para que a aprendizagem aconteça de forma colaborativa.

Segundo Santos (2020), a aquisição do conhecimento pode se dar por meio da educação ou da experiência, sendo uma construção permanente que tanto permite como facilita, para os indivíduos, a realização de tarefas intensivas. Uma das possibilidades de proporcionar ao estudante a aproximação da teoria com a prática (experiência) na construção do conhecimento, assim como seu espaço de protagonista no processo de ensino e aprendizagem, está na inclusão da extensão nos currículos (ALMEIDA; BARBOSA, 2019). 
Assim, pensar a curricularização da extensão demanda ter em mente seus três principais atores: estudantes, educadores e setor externo. Segundo Dalmolin e Vieira (2015), é um processo que, articulado com a indissociabilidade entre ensino, pesquisa e extensão, exige uma reflexão da vocação das instituições de educação superior, cujos currículos, assim como nos demais níveis e modalidades de ensino, devem estar pautados na promoção da qualidade de vida dos cidadãos, em todas as dimensões.

Em 2018, a Resolução CNE/CES no 7 estabeleceu as Diretrizes para a Extensão na Educação Superior Brasileira, regimentando o disposto na Meta 12.7 da Lei no 13.005, de 2014, que aprovou o Plano Nacional de Educação PNE 2014-2024. Atender a estas novas normas, além da obrigatoriedade, trazem possibilidades de novas metodologias de ensino dos conhecimentos do currículo dos cursos de graduação. Por meio da extensão, os educadores e estudantes se desprendem da zona de conforto e transcendem as paredes da sala de aula, para tornar a experiência educativa parte da sociedade em que se inserem. A mudança exige da comunidade acadêmica mobilização coletiva, tempo para a sensibilização, eliminação de resistências e do anseio ao novo (DALMOLIN; VIEIRA, 2015).

Dentro desse contexto, o objetivo do presente trabalho é analisar uma proposta de curricularização da extensão desenvolvida na unidade curricular "Desenvolvimento de Coleção Avançado", no Curso Superior de Tecnologia em Design de Moda do IFSC-Araranguá em contexto de pandemia. A pesquisa foi delineada visando 0 atendimento dos seguintes objetivos específicos: fundamentar a curricularização da extensão, avaliar os resultados da implementação da proposta de curricularização da extensão na unidade curricular estudada e avaliar os impactos da proposta junto aos discentes.

\section{Fundamentos da curricularização da extensão}

Em termos regulatórios, a Constituição da República Federativa do Brasil de 1988 em seu Art. 207 aborda que as universidades estarão sob o princípio da indissociabilidade entre ensino, pesquisa e extensão. Já a Lei no 9.394, de 1996, versa sobre as diretrizes e bases da educação nacional. Em seu Art. 43, consta a finalidade da educação superior, destacando-se o trecho que se refere especificamente à extensão:

VII - promover a extensão, aberta à participação da população, visando à difusão das conquistas e benefícios resultantes da criação cultural e da pesquisa científica e tecnológica geradas na instituição.

VIII - atuar em favor da universalização e do aprimoramento da educação básica, mediante a formação e a capacitação de profissionais, a realização de pesquisas pedagógicas e o desenvolvimento de atividades de extensão que aproximem os dois níveis escolares (Incluído pela Lei No 13.174, de 21 de outubro de 2015) (BRASIL, 1996). 
Ao que concerne à Educação Profissional, Científica e Tecnológica (EPCT), a Lei no 11.741, de 2008, altera os dispositivos da Lei no 9.394, de 1996 e, no Art. 39, apresenta "A educação profissional e tecnológica, no cumprimento dos objetivos da educação nacional, integra-se aos diferentes níveis e modalidades de educação e às dimensões do trabalho, da ciência e da tecnologia". Dessa forma, a Educação EPCT, na modalidade de educação superior, compartilha das finalidades relacionadas à extensão da Lei no 9.394, de 1996. A curricularização tornou-se obrigatória nas Instituições de Ensino Superior (IES) federais com a Lei no 10.172, de 2001, que aprovou o Plano Nacional de Educação (PNE) com vigência de dez anos.

Já no PNE 2014-2024 (Lei No 13.005, de 2014) consta essa exigência para todas as IES, não apenas as federais (GAVIRA; GIMENEZ; BONACELLI, 2020). O PNE 2014-2024 apresenta vinte metas e suas respectivas estratégias para a política educacional brasileira, compreendendo o período de 2014 a 2024. Dentre essas, destacam-se a meta 12 e a estratégia 12.7: "assegurar, no mínimo, $10 \%$ (dez por cento) do total de créditos curriculares exigidos para a graduação em programas e projetos de extensão universitária, orientando sua ação, prioritariamente, para áreas de grande pertinência social" (BRASIL, 2014).

Apesar da previsão datar ainda de 2001, a regulamentação da curricularização da extensão se deu apenas com a Resolução CNE/CES no 7, 2018, a qual define as Diretrizes para a Extensão na Educação Superior Brasileira e regimenta o disposto na Meta 12.7 da Lei no 13.005, de 2014, aprovada com base no parecer CNE/CES no 608, de 2018. Segundo o Art. $3^{\circ}$ da Resolução:

A Extensão na Educação Superior Brasileira é a atividade que se integra à matriz curricular e à organização da pesquisa, constituindo-se em processo interdisciplinar, político educacional, cultural, científico, tecnológico, que promove a interação transformadora entre as instituições de ensino superior e os outros setores da sociedade, por meio da produção e da aplicação do conhecimento, em articulação permanente com o ensino e a pesquisa (BRASIL, 2018).

Mais recentemente, em 2020, o Fórum de Pró-Reitores de Extensão (FORPROEXT) e o Fórum de Dirigentes do Ensino (FDE) da Rede Federal de Educação Profissional, Científica e Tecnológica (RFEPCT) publicaram as Diretrizes para a Curricularização da Extensão na RFEPCT. Segundo o documento, "a extensão é um processo educativo, cultural, político, social, científico e tecnológico que promove a interação dialógica e transformadora entre as instituições e a sociedade, levando em consideração a territorialidade" (CONIF, 2020, p.2). Recentemente, conforme Resolução CNE/CES No 1, de 29 de dezembro de 2020, prorrogou-se o prazo de implantação da Resolução CNE/CES No 7, de 2018 para 2021.

No IFSC, o tema é regido internamente pela Resolução CONSUP no 40, de 29 de agosto de 2016, que apresenta as diretrizes para inclusão das atividades de extensão nos currículos dos cursos de graduação. Na instituição, o processo de curricularização da extensão iniciou em 2015, com a primeira 
regulamentação sobre o assunto - Resolução CONSUP no 35, de 2015. A resolução atual apresenta as diretrizes, porém a adequação e a construção dos Projetos Pedagógicos dos Cursos (PPCs) são de responsabilidade do Núcleo Docente Estruturante (NDE) de cada curso, atendendo às respectivas realidades e atuações (FRUTUOSO; JULIANI, 2020).

Vale destacar que, segundo o Fórum de Pró-Reitores de Extensão das Universidades Públicas Brasileiras - FORPROEX (2012), as Diretrizes para as Ações de Extensão (também chamadas, devido às iniciais, de 5Is) são: interação dialógica, interdisciplinaridade e interprofissionalidade, indissociabilidade ensino, pesquisa e extensão, impacto na formação do estudante, impacto e transformação social.

Ao tratar sobre o papel da extensão, a interação dialógica se destaca na obra de Freire (2015), na medida em que, segundo o autor, a educação se dá pela comunicação, em um encontro entre sujeitos que sentem, percebem e transformam constantemente a realidade. Segundo o autor, o conhecimento não se dá pela transferência do saber de um sujeito a outro, como se o último fosse um receptor, um papel em branco, incapaz de ensinar, atendo-se à repetição:

Ao contrário, educar e educar-se, na prática da liberdade, é tarefa daqueles que sabem que pouco sabem - por isso sabem que sabem algo e podem assim chegar a saber mais - em diálogo com aqueles que, quase sempre, pensam que nada sabem, para que estes, transformando seu pensar que nada sabem em saber que pouco sabem, possam igualmente saber mais (FREIRE, 2015, p. 19).

O verdadeiro aprendizado se dá quando o indivíduo é provocado a problematizar, desafiado a refletir sobre sua situação concreta, apropriando-se do conhecimento e aplicando-o na transformação do meio e, consequentemente, transformando a si no processo. Nesse sentido, a aula transforma-se em um encontro de troca de conhecimentos e coparticipação dos sujeitos, em uma situação gnosiológica, de incentivo ao pensar reflexivo e não à repetição e memorização, como explica o autor:

Para nós, a "educação como prática da liberdade" é, sobretudo e antes de tudo, uma situação verdadeiramente gnosiológica. Aquela em que o ato cognoscente não termina no objeto cognoscível, visto que se comunica a outros sujeitos, igualmente cognoscentes. Educador-educando e educando-educador, no processo educativo libertador, são ambos sujeitos cognoscentes diante de objetos cognoscíveis, que os mediatizam (FREIRE, 2015, p. 92).

Segundo De Camilloni (2018), a extensão deve ser dar em situações autênticas, com base na experiência e na interdisciplinaridade, comprometida com a vida real, junto da comunidade. A autora relaciona a prática ao conceito de multiletramento, cunhado pelo New London Group, em que há uma intensa troca linguística e cultural, em diferentes contextos sociais. Para além disso, 
vislumbra-se nessas ações um estímulo ao pensamento reflexivo e ao desenvolvimento do espírito científico (COSTA, 2010).

A interdisciplinaridade é inerente a essas ações, pelo trabalho não ser compartimentado. Ela promove o desenvolvimento de competências no sentido de que demanda um aprendizado que equilibre os postulados teóricos às práticas, permitindo um diálogo de construção do saber-fazer (ALLAIN; WOLLINGER; GRUBER, 2019).

Por tudo isso, a extensão não deve ser vista apenas como uma obrigação legal, mas como uma estratégia para aperfeiçoar e possibilitar a prática por meio da indissociabilidade, construindo-se um currículo integral e de estrutura flexível (DE CAMILLONI, 2018; GAVIRA, GIMENEZ, BONACELLI, 2020). Assim, a educação por meio da experiência, com problemas reais, dará abertura a sucessos, fracassos e tentativas, que resultarão em aprendizados vivenciados e avaliados pelos participantes (DE CAMILLONI, 2018).

\section{Contextualização da proposta de curricularização da extensão para o Curso Superior de Tecnologia em Design de Moda do IFSC-Araranguá}

Segundo Aizpun, Sandino e Merideno (2015), o mundo do trabalho exige dos estudantes algumas habilidades para a solução de problemas, como trabalho em equipe, liderança e criatividade. As instituições de ensino, por sua vez, buscam formas de possibilitar-Ihes a experiência prática, trazendo maior sentido para o conhecimento transmitido em sala de aula. Uma das possibilidades para promover atitudes relacionadas, por exemplo, à criatividade na solução de problemas reais está na Colaboração Universidade-Indústria (UniversityIndustry Collaboration - UIC) (AIZPUN; SANDINO; MERIDENO, 2015).

O Plano de Desenvolvimento Institucional (PDI) do IFSC 2020-2024 apresenta uma marcante concepção de relacionamento com os setores da sociedade, compreendendo que, para o cumprimento de sua missão, é necessário empreender esforços para fortalecer e ampliar suas relações com a comunidade. Essa aproximação com os diversos atores da sociedade qualifica o ensino e impulsiona as atividades de pesquisa e de extensão.

Para que os educadores elaborem projetos para a curricularização da extensão ao longo da caminhada formativa do estudante, é preciso um estreito alinhamento com o setor externo, em um contínuo desenvolvimento de programas e projetos de extensão. Tal articulação proporciona à tríade extensionista o valor da aproximação e o atendimento aos 5Is da extensão (FORPROEX, 2012). Essa integração oferece ao estudante a possibilidade de vivenciar demandas do mundo real, reforçando a conexão com os aprendizados adquiridos em seus respectivos cursos de formação. Dessa forma, a proposta aqui em análise baseia-se na Resolução CONSUP no 40, de 2016, utilizando-se de uma unidade curricular não específica de extensão do curso superior de Tecnologia em Design de Moda do Câmpus Araranguá do IFSC.

A caracterização da extensão no IFSC se dá pelo atendimento a Resolução CONSUP/IFSC no 61, de 2016. Segundo o documento, é necessário que a 
proposta atenda às diretrizes citadas anteriormente como os 5Is (FORPROEXT, 2012), o que retomaremos adiante.

A proposta em questão caracterizou-se como um projeto de extensão com carga horária mínima de 40 horas, conforme a definição do mesmo documento:

Deve conter objetivos geral e específicos, claros e tangíveis, indissociáveis da pesquisa e do ensino, com a atuação de discentes e servidores e a participação da comunidade externa, alinhados ao Planejamento Estratégico do IFSC (IFSC, 2016).

No quesito da tríade extensionista, no caso em tela eram os seguintes os atores: a) estudantes da unidade curricular de Desenvolvimento de Coleção Avançado; b) docente da unidade curricular, assim como docentes convidados a desenvolver material complementar e a participar da banca avaliativa; c) colaboradores e proprietários de empresas do Núcleo de Moda Sul Catarinense (NMSC), que atuaram como mentores dos estudantes e avaliadores nas bancas. O núcleo, criado em 2005, está situado em Criciúma e representa empresários da área têxtil e de confecção de toda a região Sul de SC, desde Laguna até Passo de Torres (TNSUL, 2017); d) profissionais da área de desenvolvimento de coleção em empresas de confecção, participantes da banca avaliativa e ministrantes de palestras.

\section{Metodologia}

O quadro metodológico que guia o desenvolvimento do estudo segue a abordagem qualitativa. De acordo com Gerhardt e Silveira (2009, p. 34), quando se utilizam dessa perspectiva metodológica, os pesquisadores "[...] buscam explicar o porquê das coisas, exprimindo o que convêm ser feito, mas não qualificam os valores e as trocas simbólicas e nem se submetem à prova de fatos, pois os dados analisados são não-métricos".

Dada a natureza do objetivo da pesquisa, se caracteriza por exploratória, visto maior familiaridade das pesquisadoras com o problema, aprimorando descobertas e ideias e, de planejamento flexível. Trata-se de uma pesquisaação, em virtude da participação das pesquisadoras de forma protagonista, assim como de um grupo de pessoas relacionadas diretamente com o problema coletivo em estudo (GIL, 2017).

O período de atividades da unidade curricular aqui analisada ocorreu de 10 de março a 30 de agosto de 2020. Os instrumentos para a coleta de dados primários envolveram aplicação de questionário online (Google Forms) enviado aos 20 estudantes da unidade curricular de Desenvolvimento de Coleção Avançado do curso Superior de Tecnologia em Design de Moda do IFSC, câmpus Araranguá no primeiro semestre de 2020, correspondente ao quinto semestre do curso. Houve retorno de 19 respostas, identificadas pela letra $D$ (discente) e o número, conforme a ordem de resposta do questionário. A análise está pautada na verificação da experiência dos estudantes, assim como no texto do Art. $5^{\circ}$ da Resolução CNE/CES no 7, de 2018. 


\section{Resultados e discussões}

Esta experiência teve início na primeira aula da disciplina de Desenvolvimento de Coleção Avançado, em 12 de março de 2020, em uma sala de teatro, o que possibilitou a distribuição em grupos de trabalho. Cada grupo realizou um brainstorming sobre as carências, dificuldades e aprendizados dos alunos do curso de Tecnologia em Design de Moda do câmpus Araranguá do IFSC em relação ao desenvolvimento de uma coleção.

A atividade deixou claros os pontos nos quais os estudantes tinham dificuldade, o que deu subsídio à docente para planejar a unidade curricular. A proposta foi organizada de modo a possibilitar a cada discente que, no decorrer do semestre, gradualmente descobrisse se o que cogitara no início da unidade curricular aconteceu de fato no processo de desenvolvimento de sua coleção.

Após a exposição dos resultados do brainstorming para o grande grupo, em círculo, construiu-se com toda a turma o Planejamento e Desenvolvimento de Produto (PDP) de uma empresa de confecção, a partir do conhecimento prévio dos discentes. A coleção elaborada foi, posteriormente, desenhada em formato digital no programa Bizagi, com apoio da professora.

No depoimento de um dos discentes, abaixo apresentado, é possível verificar que a proposta trouxe resultados positivos:

[...] desde a primeira aula tu já me surpreendeu com aquela roda de conversa, super disposta a ouvir as nossas dores e programar o desenvolvimento e as atividades da disciplina ouvindo as nossas opiniões e de forma que se tornasse confortável para nós alunos. Aquela primeira aula para mim foi extremamente significativa, tamanha compreensão que senti da tua parte diante todos os relatos, me senti mais leve e sem tanto medo de errar [...] (D19).

Na sequência, com uma lista de empresas do Núcleo de Moda Sul Catarinense (NMSC) interessadas em participar do projeto, os discentes escolheram a empresa que melhor se adequava a seu perfil de trabalho. Foi facultado aos estudantes sugerir outra empresa da região, a partir da sua aproximação, como por exemplo vínculo de trabalho. Para apoiar a experiência de desenvolver uma coleção para uma marca já existente no mercado, os colaboradores ou empresários das respectivas empresas prestaram, dentro do possível, mentoria aos discentes, e realizaram, junto com outros profissionais, a avaliação final dos trabalhos. A partir da escolha da empresa, foram coletados materiais e dados complementares sobre a marca para o início do desenvolvimento de coleções.

Com esses dados e com o material coletado nas redes sociais, site e com os profissionais da empresa/marca escolhida, os estudantes construíram o mix de produto da coleção em uma planilha de Excel, cujo modelo foi disponibilizado pela docente. O mix de produto é uma ferramenta que contribui para o planejamento da coleção e a definição das peças que serão desenhadas e confeccionadas. 
Uma das alunas, que tem experiência profissional com desenvolvimento de mix de produto, apresentou à turma a realidade da empresa em que atua. Nesta ocasião, foi perceptível a curiosidade dos demais discentes em saber ainda mais sobre a experiência da colega.

Na sequência, os discentes desenvolveram painéis de persona e tema, além de um caderno de inspiração (sketchbook) referente à empresa/marca escolhida. O painel de persona apresenta a representação do consumidor da marca, enquanto o painel de tema ilustra a inspiração temática da coleção. 0 trabalho dos painéis e textos foi avaliado pela professora, apontando as necessidades de melhorias e possibilitando aos discentes refazê-lo, de modo a adquirir a expertise da atividade. Foram realizadas avaliações parciais que consistiram na entrega de pequenas atividades, para distribuir o projeto ao longo do semestre e evitar o acúmulo de atividades ao final do período. Este procedimento possibilitou o feedback e oportunidades aos estudantes de refazer a atividade, refletindo sobre os pontos de melhoria.

Os critérios de avaliação dos trabalhos foram os seguintes: desenvolvimento do texto, painel de persona e tema, criatividade, inovação e cuidado com os detalhes do trabalho. Além da avaliação quantitativa, com atribuição de nota, também foram entregues observações escritas para proporcionar maior entendimento das melhorias a serem desenvolvidas.

Buscou-se saber a percepção dos estudantes acerca do desenvolvimento da unidade curricular por meio de questionário aplicado com a turma. Percebese, pelas respostas, o quão importante foi o feedback das atividades realizadas. Esse item recebeu 15 votos dos discentes como destaque dentre as atividades desenvolvidas de apoio ao processo de aprendizagem, conforme o gráfico da Figura 1.

Figura 1: feedback dos estudantes quanto às atividades desenvolvidas na unidade curricular

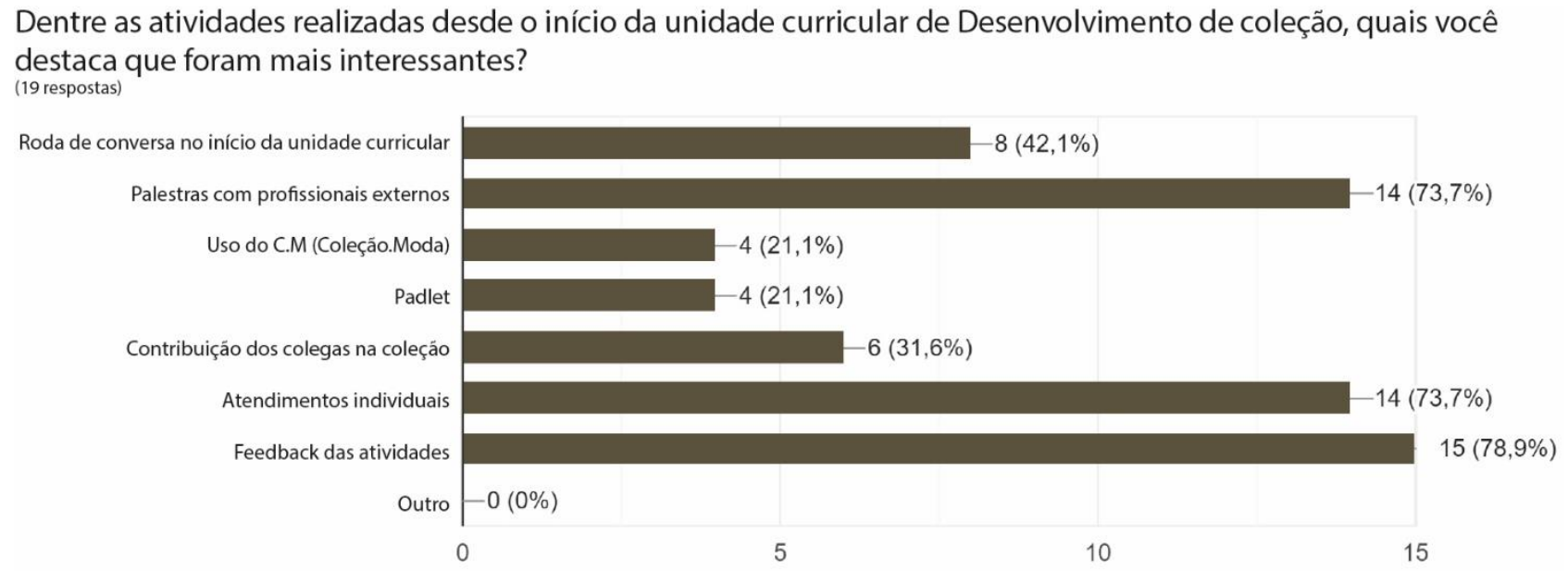

Fonte: elaborado pelas autoras (2021). 
Outro destaque quanto à avaliação dos estudantes acerca do desenvolvimento das atividades de apoio a disciplina, que recebeu 14 votos, foi a realização de atendimentos individuais. Cada estudante traz conhecimentos prévios e tem um ritmo próprio e, nesse sentido, o atendimento online individual aproximou docente e discentes e permitiu atender as dificuldades de forma personalizada. Considerando que cada um tinha horário marcado para o atendimento e as atividades eram não presenciais em função da pandemia, isso otimizou o tempo de todos porque não gerou aos demais discentes a necessidade de aguardar seu atendimento, como aconteceria em aulas presenciais. Conforme o D9, "o atendimento com a professora foi essencial para o desenvolvimento da minha coleção e o material estava ótimo".

Ainda, como se observa na Figura 1, destacam-se as palestras com profissionais externos na preferência da turma. Para possibilitar um contato ainda maior com o mundo de trabalho e um entendimento mais aprofundado sobre cada etapa do PDP, foram convidados profissionais de diferentes áreas. A participação se deu de forma virtual, possibilitando trazer profissionais de diferentes cidades, estados e países.

Com a realidade que a pandemia trouxe, esse contato com profissionais de diferentes partes do mundo acabou tornando-se mais frequente nas redes sociais, com a realização de lives e palestras online. Assim também participou nesta experiência uma designer de marcas e diretora criativa de Florianópolis e, que no momento da palestra estava morando na Espanha, ela conversou com a turma sobre branding. Ainda foi realizada uma palestra com uma empresária de uma plataforma de moda, que falou sobre planejamento de produto e tendências de moda por meio da plataforma desenvolvida pela empresa. A plataforma foi disponibilizada gratuitamente para teste por algumas semanas para os estudantes realizarem a pesquisa de tendências.

Outras atividades ainda foram realizadas. Um docente da área de Moda do IFSC gravou vídeos para os estudantes, trazendo informações sobre os tecidos e suas possíveis aplicações no desenvolvimento de coleção. Uma egressa do curso, profissional da área de desenvolvimento de estampa, fez uma oficina com os estudantes sobre desenvolvimento de rapport (estampa corrida). Ambos foram apontados pelos estudantes como como essenciais para preencher as lacunas de conhecimento que haviam apontado no primeiro encontro da unidade curricular. Conforme a avaliação dos estudantes, essa interação com profissionais de outras áreas, cidades e país, foi muito positiva para o compartilhamento de conhecimento.

Os discentes fizeram o desenvolvimento de desenho dos produtos, os quais expressavam a persona da marca, o tema e toda a pesquisa apresentada no sketchbook. O método de avaliação/contribuição nesse momento contou com a participação dos pares (colegas) e com a ferramenta Padlet. Após receber o feedback dos colegas e da professora, cada estudante seguiu para a finalização dos desenhos e construção da ficha técnica.

Percebendo que alguns estudantes não tinham domínio de nenhum software CAD/CAM para os painéis e desenhos técnicos, buscou-se apresentar 
algumas alternativas, como o software livre InkScape e o software com possibilidade de uso gratuito por 60 dias Audaces Idea. A utilização dos softwares para alguns discentes foi positiva: "Eu diria que a indicação do InkScape mais no início das aulas seria maravilhosa. [...] que agora ninguém tira esse aplicativo 'mara' do meu computador hahaha, que venham os próximos painéis e coleções!" (D2). Porém alguns estudantes tiveram dificuldade com o uso, pois não tinham acesso aos computadores no câmpus, devido às atividades não presenciais (ANP), precisando utilizar as ferramentas disponíveis em casa: "[...] o meu computador não é potente para esses softwares, então perdi vários templates e vários trabalhos em andamento porque o aplicativo travava, ou meu computador não suportava e fechava sem salvar" (D4).

Cada estudante possuía uma pasta individual na plataforma Google Drive, na qual ficavam os trabalhos desenvolvidos com todas as versões de melhorias. Assim, foi possível verificarmos a evolução dos trabalhos. Como não aconteceram as apresentações dos trabalhos em sala de aula, a pasta também foi uma forma de os estudantes conhecerem o trabalho dos colegas e se inspirarem para o desenvolvimento de seus trabalhos.

Finalmente, no intuito de contribuir para os estudantes construírem seu portfólio, o trabalho final de cada um foi postado na plataforma Behance, muito utilizada por designer, artistas e arquitetos para apresentar seus trabalhos profissionais. A avaliação final contou com a participação de outros professores e de profissionais externos, inclusive das empresas/marcas selecionadas, em uma banca online.

A escolha dos professores e profissionais externos tomou como base seu segmento de atuação estar em consonância com o segmento de confecção escolhido pelo estudante. Foram enviados convites para realizar a avaliação, e foi definido, preferencialmente, um avaliador diferente por estudante. Os empresários e colaboradores que já estavam acompanhando o desenvolvimento das coleções foram priorizados. A avaliação de outros professores e profissionais externos ocorreu via Google Forms.

No retorno dos avaliadores, os pontos que chamaram a atenção para aperfeiçoamento das estratégias de desenvolvimento do projeto foram a criatividade e a inovação das coleções. Verificou-se, conforme Figura 2, que, segundo uma percepção geral dos avaliadores, um ponto que precisa ser aperfeiçoado no aprendizado dos estudantes é: como pensar uma coleção comercial de forma criativa e inovadora. 
Figura 2: Retorno dos avaliadores quanto à criatividade e inovação das coleções A coleção apresentou criatividade e inovação? 21 respostas

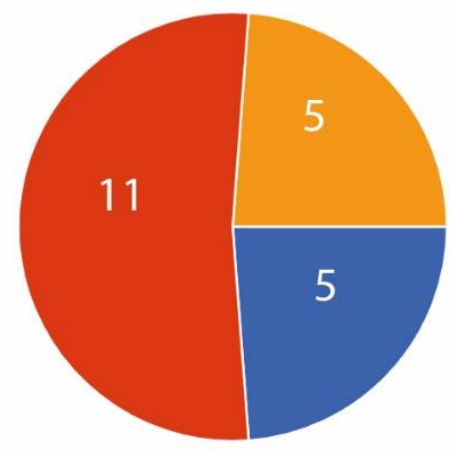

Não apresentou criatividade e inovação. (0.0 pontos)

Apresentou criatividade, mas faltou inovação. ( 0.50 pontos)

Apresentou criatividade e inovação na coleção desenvolvida. (1.0 pontos)

Fonte: elaborado pelas autoras (2021).

Para além disso, analisar o sucesso ou as falhas de uma unidade curricular depende, fundamentalmente, do feedback do público ao qual ela se destina: os estudantes e a comunidade externa. Ao se tratar das contribuições da experiência aqui em análise para a formação profissional, foi feita a seguinte pergunta no questionário enviado: Você acredita que a unidade curricular de Desenvolvimento de Coleção Avançado agregou no seu conhecimento profissional? Como? Os discentes destacaram que é uma unidade curricular relevante para seu desenvolvimento profissional, conforme os depoimentos abaixo.

Bastante, considero uma das matérias mais importantes para formação pelas pesquisas realizadas em desfiles de marcas mais famosas, inspirações e conhecimento de diversos estilos da moda mais aprofundado por pensar que está fazendo uma coleção sua. Principalmente em casa com mais tempo mais calma e conforto para pesquisar melhor o que estou conhecendo e criando. Também por ter dado a oportunidade de conversar diretamente com as estilistas da marca compartilhando experiências da parte dela e dicas (D14).

[...] está foi a primeira vez ao longo do curso, em que consegui sentir como é de fato desenvolver uma coleção dentro do mercado de trabalho. Isso é muito importante para que nós, alunos, possamos sair da faculdade com mais noção daquilo que nos espera no mercado, a forma como devemos agir ao entrar numa empresa, buscando conhecê-la, mergulhar de cabeça no "mundo" da marca e do público, pra conseguir desenvolver o melhor trabalho possível sempre pensando no público-alvo/persona da marca (D19). 
Quando perguntados quanto à visão sobre o projeto finalizado - onde teve mais facilidade e onde teve mais dificuldade de execução, as respostas foram diversas em todo o processo, com destaque ao uso dos softwares. Segundo D3, "Com certeza, a parte criativa me pega mais, tenho bastante dificuldade em ser criativa e evitar a 'cópia', acho que prefiro a parte mais técnica da criação", enquanto D5 afirmou: "Facilidade eu acho que não tive em nenhuma parte, um pouco talvez na ficha técnica. Minhas maiores dificuldades foram para fazer os painéis e o layout, pois não tive aula de software ainda e na parte de desenvolvimento das peças".

A utilização foi mesmo um desafio, pois o curso não teve como adaptar a unidade curricular focada na utilização dos softwares às ANP da pandemia e, portanto, a turma ainda não tinha tido contato com esses conhecimentos. A partir disso, destaca-se a importância da unidade curricular que aborda o uso de softwares ser ofertada mais cedo na grade curricular, possibilitando ao discente adquirir tal habilidade antes da experiência de extensão.

Finalmente, questionou-se se o discente se sente hoje preparado para um novo projeto de coleção. Na grande maioria as respostas foram positivas, apresentando ainda algumas inseguranças, conforme os depoimentos abaixo:

Sim, pois acredito que compreendi os processos de criar uma coleção do início com um tema que tenha a ver com o público da marca (D2).

Ainda não $[\ldots]$, sabe aquele medo de desenvolver algo feio, que não chame a atenção de forma positiva?! Esse é meu medo, mas estou ansiosa para o projeto da sexta fase, mesmo com medo (D3).

Agora vejo mais a importância da unidade de coleção até para montar um catálogo, ordem de desfile ou vitrine. Tudo isso eu não tinha tanta noção. Claro que vai muito do direcionamento, tendo objetivo, tema e meta definidos, a coleção fica muito mais fácil de se elaborar. Gostei muito da ideia de criar um cronograma de execução (que peguei da matéria de Fundamentos de Marketing (D11).

Dentre outras contribuições que os discentes deixaram está a elaboração de mais videoaulas; auxílio com softwares; maior alinhamento com as marcas, pois alguns colaboradores/empresários não conseguiram despender tempo para a mentoria; mais opções de marcas para a escolha inicial; e maior contato com a prática por meio de visitas técnicas.

O trabalho em ANP foi um desafio para docentes e discentes. Na Figura 3 , consta o feedback dos estudantes em relação às ANP. 
Figura 3: Considerações dos estudantes sobre as aulas em ANP

Você conseguiu desenvolver os trabalhos da Unidade Curricular?

19 respostas

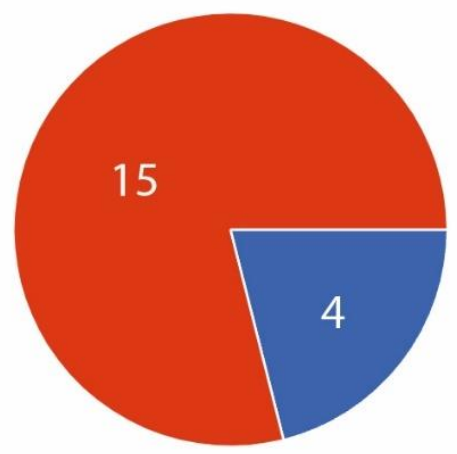

Sim, não tive problemas em realizar as atividades não presenciais (ANP)

Sim, porém com alguns problemas (equipamento, internet, falta de concentração ou outros)

Não

Fonte: elaborado pelas autoras (2021)

Verifica-se, na Figura 3, que quatro estudantes conseguiram realizar as atividades no formato não presencial sem problemas, enquanto 15 estudantes tiveram algum tipo de dificuldade. Dentre elas, foram relatadas: falta de concentração, o cansaço do trabalho diurno, isolamento, sentimentos gerados pela pandemia, perda familiar, desmotivação devido à preferência pelo presencial, necessidade de autonomia, e computador que não suportava a instalação de softwares de desenho.

Para atendimento aos discentes e ao trabalho a ser desenvolvido por eles em formato ANP, buscou-se o uso de ferramentas diversas como: Google Meet, Hangout, Whatsapp, Google drive, Youtube, Audaces Idea, InkScape, Coleção.Moda, Padlet e Behance. Dentro das possibilidades, as adaptações foram positivas, segundo a visão dos discentes:

[...] mesmo com as "dificuldades" do EaD, achei super legal teu empenho como professora de trazer coisas diferentes para as aulas, pessoas, ferramentas... tive dificuldades no contato com a marca nas últimas semanas mas creio que não interferiu no desenvolvimento como um todo e sim só no bate-papo com a marca (D12).

A participação de empresários e colaboradores das empresas/marcas, inicialmente prevista, também foi impactada pela pandemia, visto a importância das empresas em atender aos protocolos de saúde e se reinventar mediante as necessidades e restrições apresentadas pelo contexto pandêmico. Além disso, visitas nas empresas não foram possíveis e o contato com os profissionais disponíveis foi por meio de mídias sociais e e-mail.

A interação dialógica da comunidade acadêmica com a sociedade enriquece a formação profissional dos estudantes e diminui distâncias entre os atores de uma atividade de extensão, como pode ser observado pelo depoimento 
de uma das empresárias que participou como mentora no desenvolvimento de coleção. concedido a uma matéria publicada no site do IFSC Araranguá.

Em primeiro lugar fiquei muito feliz em ser uma marca escolhida. Acho que uma instituição de ensino e empresas locais atuando juntas aproximam o aluno da realidade do mercado de trabalho. No caso da [cita nome da estudante], ela foi muito sensível e muito apurada no trabalho, conseguiu mergulhar no conceito da marca e desenhar peças muito coerentes com o perfil [cita nome da empresa]", afirma empresária, mentora da unidade curricular (IFSC, 2020).

A participação do setor externo visa atender as Diretrizes da Extensão, conforme disposto no Art. 50 da Resolução CNE/CES No 7, de 2018: "I - a interação dialógica da comunidade acadêmica com a sociedade por meio da troca de conhecimentos, da participação e do contato com as questões complexas contemporâneas presentes no contexto social".

Com a proposta apresentada, atendeu-se também ao inciso II do mesmo artigo: "formação cidadã dos estudantes, marcada e constituída pela vivência dos seus conhecimentos, que, de modo interprofissional e interdisciplinar, seja valorizada e integrada à matriz curricular". A ilustração desse item se dá tanto no início da unidade curricular, em que se colocou em uma roda de discussão os conhecimentos do grupo para subsidiar a unidade curricular, assim como no convite a uma das estudantes para expor sua experiência profissional sobre mix de produto.

Em um curso da área da Moda, o desenvolvimento de uma coleção voltada para a realidade profissional valoriza e instiga o saber-fazer. Ao considerar-se, inclusive, que há na turma discentes já atuantes na área, abrese a possibilidade ainda maior do protagonismo discente e de um encontro de sujeitos, todos aptos a contribuir (FREIRE, 2015).

Essa metodologia ativa, em que o estudante se torna protagonista, possibilita uma reflexão sobre o papel do docente no espaço escolar e dos setores externos. Nesse sentido, a responsabilidade por uma formação cidadã se dá na relação dessa tríade extensionista. Conforme a diretriz apresentada no inciso III do Art. $5^{\circ}$ da Resolução CNE/CES No 7, de 2018: "III - a produção de mudanças na própria instituição superior e nos demais setores da sociedade, a partir da construção e aplicação de conhecimentos, bem como por outras atividades acadêmicas e sociais".

Em todo esse processo é nítido o atendimento também ao inciso "V - a articulação entre ensino/extensão/pesquisa, ancorada em processo pedagógico único, interdisciplinar, político educacional, cultural, científico e tecnológico".

\section{Considerações finais}

O presente trabalho teve como objetivo a análise de uma proposta de curricularização da extensão desenvolvida na unidade curricular 
"Desenvolvimento de Coleção Avançado", no Curso Superior de Tecnologia em Design de Moda do câmpus Araranguá do IFSC. Em um primeiro momento, a fundamentação da curricularização da extensão possibilitou entender o contexto de legislação vigente tanto em âmbito nacional como institucional. Passou-se, então, para a apresentação do espaço e contexto de desenvolvimento da proposta, para finalmente seguir-se a análise da experiência realizada com os discentes e profissionais participantes da unidade curricular.

A primeira consideração a ser destacada é a flexibilidade que a extensão exige na sua execução, principalmente por se tratar de atividades com grande nível prático e que envolvem diferentes esferas e atores da sociedade. Nesta experiência, a necessidade de adaptar a forma de ensino do presencial para o não presencial foi um grande desafio, mas também uma oportunidade de aprender e aplicar novas ferramentas. A atividade não presencial possibilitou um atendimento individualizado, pautado nas dificuldades e necessidades de cada estudante. Foi necessário perceber o progresso de aprendizado de cada um, 0 que ditou o ritmo das atividades e das entregas das tarefas. Para um sucesso maior no atendimento individualizado, considerando turmas com em torno de 20 estudantes, sugere-se para experiências futuras a atuação de dois docentes.

Em função das ANP e do contexto de pandemia, houve também uma dificuldade maior na contribuição dos empresários e colaboradores das empresas na mentoria dos estudantes. Mas entende-se que foi um momento difícil para a indústria de confecção. Alguns conseguiram dar prosseguimento na conexão com os estudantes, outros não. Para uma próxima oportunidade, a sugestão é abrir um cadastro de empresas de todo o país, dando mais possibilidades aos discentes quanto a estilos de marca e um melhor alinhamento entre estudantes e profissionais durante todo o semestre.

Ademais, verificou-se que é possível, sim, utilizar-se da extensão para aproximar os estudantes de um aprendizado com significado e tornar todos os participantes sujeitos ativos na proposta extensionista. A inclusão da extensão no currículo possibilita às instituições de ensino reflexões sobre o percurso formativo do estudante, incluindo os três atores base da extensão: estudantes, educadores e setor externo. Pensar a extensão no currículo pode gerar angústias, principalmente quando se depara com o cálculo do quantitativo de horas, que desafia a pensar em como garantir que todos os semestres seja possível a participação do setor externo.

Esta inquietude é causada pela necessidade ou "obrigatoriedade" da mudança da metodologia quando da inclusão da extensão. É neste momento que se encontra a educação, no momento de repensar seu formato, de revisitar estudiosos que já há muito falam desta necessidade de mudança, como Freire (2015). O currículo precisa fazer sentido para o educador, mas principalmente para o educando e para a sociedade na qual estão inseridos.

O ponto inicial para a revisão de um projeto pedagógico está em entender as demandas do entorno e da comunidade em que está inserido o curso e quais as competências pretende-se que o egresso desenvolva a partir de sua experiência formativa. Importante observar que esses sujeitos, discentes e setor 
externo, têm suas experiências sociais e saberes que são diversos e precisam ser ouvidos para que a aprendizagem aconteça de forma flexível e colaborativa.

A extensão, por sua vez, tira educadores e estudantes de sua zona conforto e transcende as paredes da sala de aula para tornar a experiência parte de um todo maior. Seu planejamento possibilita treinar um olhar atento e sensível às demandas da realidade, as quais podem ser trabalhadas por meio da tríade presente nos Projetos Pedagógicos de Curso: a indissociabilidade entre ensino, pesquisa e extensão.

As Diretrizes Nacionais da Extensão Universitária, trazidas pela Resolução CNE/CES No 7, de 18 de dezembro de 2018, de 2018 possibilitam então pensar a extensão por todos os cursos superiores de graduação em âmbito nacional. Para tanto, sugere-se observar quais ações já são realizadas nos cursos que possuem potencial extensionista, além de construir uma estreita relação com os setores externos e valorizar o protagonismo discente e o protagonismo da comunidade.

\section{REFERÊNCIAS}

AIZPUN, Miguel; SANDINO, Diego; MERIDENO, Inaki. Developing students' aptitudes through University-Industry collaboration. Ingeniería e investigación, v. 35, n. 3, p. 121$128,2015$.

ALLAIN, Olivier; WOLLINGER, Paulo; GRUBER, Crislaine. Por uma nova formação docente na educação profissional. V Seminário Nacional de Educação Profissional e Tecnológica. Belo Horizonte: CEFET-MG, 2019. p. 323-332.

ALMEIDA, Sinara Monica Vitalino de; BARBOSA, Larissa Marcelle Vaz. Curricularização da extensão universitária no ensino médico: o encontro das gerações para humanização da formação. Revista Brasileira de Educação Médica, v. 43, n. 1, p. 672-680, 2019.

BRASIL. Constituição da República Federativa do Brasil de 1988. Disponível em: http://www.planalto.gov.br/ccivil_03/constituicao/constituicao.htm Acesso em 17 fev. 2021.

BRASIL. Lei de Diretrizes e Bases da Educação Nacional (LDB). Lei no 9.394, de 20 dezembro de 1996. Estabelece as diretrizes e bases da educação nacional. Legislação Federal e Marginália, 1996. Brasília, DF: Presidência da República, 1996. Disponível em: http://www.planalto.gov.br/ccivil_03/leis/19394.htm. Acesso em 17 fev. 2021.

BRASIL. Plano Nacional de Educação (PNE). Lei no 10.172, de 09 de janeiro de 2001. Aprova o Plano Nacional de Educação e dá outras providências. Legislação Federal e Marginália, 2001. Brasília, DF: Presidência da República, 2001. Disponível em: http://www.planalto.gov.br/ccivil_03/leis/leis_2001//10172.htm. Acesso em 20 jan. 2021.

BRASIL. Lei No 11.741, de 16 de julho de 2008. Altera dispositivos da Lei no 9.394, de 20 de dezembro de 1996, que estabelece as diretrizes e bases da educação nacional.

Legislação Federal e Marginália, 2008. Brasília, DF: Presidência da República, 2008. Disponível em: http://www.planalto.gov.br/ccivil_03/_ato2007-2010/2008/lei/l11741.htm Acesso em: 28 de fev. 2021

BRASIL. Lei no 13.005, de 25 de junho de 2014. Aprova o Plano Nacional de Educação e dá Perspectivas em Diálogo, Naviraí, v. 09, n. 19, p. 282-300, jan./abr. 2022. 
outras providências. Brasília, DF: Presidência da República, 2014. Disponível em: http://www.planalto.gov.br/ccivil_03/_ato2011-2014/2014/lei/l13005.htm. Acesso em 25 jul. 2021.

BRASIL. Ministério da Educação. Parecer CNE/CES No 608 de 03 de outubro de 2018. Diretrizes para as Políticas de Extensão da Educação Superior Brasileira. Brasília, DF: MEC, 2018a. Disponível em: https://abmes.org.br/legislacoes/detalhe/2651/parecer-cne-ces-n-608. Acesso em: 25 agosto 2021.

BRASIL. Resolução no 7, de 18 de dezembro de 2018. Estabelece as Diretrizes para a Extensão na Educação Superior Brasileira e regimenta o disposto na Meta 12.7 da Lei no 13.005/2014, que aprova o Plano Nacional de Educação - PNE 2014-2024 e dá outras providências. Brasília, DF: Câmara de Educação Superior do Conselho Nacional de Educação, 2018b. Disponível em: https://www.in.gov.br/materia/-

/asset_publisher/Kujrw0TZC2Mb/content/id/55877808. Acesso em 28 fev. 2021.

BRASIL. Resolução CNE/CES No 1, de 29 de dezembro de 2020. Dispõe sobre prazo de implantação das novas Diretrizes Curriculares Nacionais (DCNs) durante a calamidade pública provocada pela pandemia da COVID-19. Ministério da Educação/Conselho Nacional de Educação/Câmara de Educação Superior. Disponível em: https://www.in.gov.br/en/web/dou//resolucao-cne/ces-n-1-de-29-de-dezembro-de-2020-296893578 Acesso em 20 de jan. 2021.

CONIF. Diretrizes para a Curricularização da Extensão na Rede Federal de Educação Profissional, Científica e Tecnológica. 2020. Disponível em:

https://portal.conif.org.br/br/component/content/article/84-ultimas-noticias/3704-conifestabelece-diretrizes-para-a-curricularizacao-da-extensao-na-rede-federal? Itemid $=558$. Acesso em: 20 de jan. 2021.

COSTA, Aryana Lima. A extensão na formação de profissionais de história. Revista Brasileira de História, v. 30, n. 60, p. 35-53, 2010.

DALMOLIN, Bernadete Maria; VIEIRA, Adriano José Hertzog. Curricularização da extensão: Potências e desafios no contexto da gestão acadêmica. In: EDUCERE: XII Congresso Nacional de Educação, PUCPR. 2015. p. 7186-7201.

DE CAMILLONI, Alicia WR. La integración de la participación de los estudiantes en proyectos de extensión como componente del currículo universitario. InterCambios. Dilemas y transiciones de la Educación Superior, v. 7, n. 1, 2020.

FARAONI, Monica et al. Exploring e-loyalty Antecedents in B2C e-Commerce. British Food Journal, 2019.

FIESC - Federação das Indústrias do Estado de Santa Catarina. Santa Catarina. Indicadores do Observatório FIESC - dados consolidados anualmente da RAIS (Registro Anual de Informações Sociais). 2019. Disponível em:

https://observatorio.fiesc.com.br/indicadores/empregos Acesso em: 01 de out. 2020.

FORPROEX. Política Nacional de Extensão Universitária. Manaus, 2012. Disponível em: https://proex.ufsc.br/files/2016/04/Pol\%C3\%ADtica-Nacional-de-Extens\%C3\%A3oUniversit\%C3\%A1ria-e-book.pdf. Acesso em: 22 maio 2021.

FREIRE, Paulo. Extensão ou comunicação? 17 ed. São Paulo: Paz e Terra, 2015.

FRUTUOSO, Tomé de Pádua; JULIANI, Douglas Paulesky. Caminhos para a curricularização da extensão: Ações no Instituto Federal de Santa Catarina - IFSC. Curitiba: CRV, 2020. 
GAVIRA, Muriel de Oliveira; GIMENEZ, Ana Maria Nunes; BONACELLI, Maria Beatriz Machado. Proposta de um sistema de avaliação da integração ensino e extensão: um guia para universidades públicas brasileiras. Avaliação: Revista da Avaliação da Educação Superior (Campinas), v. 25, n. 2, p. 395-415, 2020.

GERHARDT, Tatiana; SILVEIRA, Denise. Métodos de Pesquisa. UFRGS, 2009. Disponível em: https://lume.ufrgs.br/bitstream/handle/10183/52806/000728684.pdf?sequence $=1$ \&isAllowed $=$ y. Acesso em 11 fev. 2021.

GIL, Antonio Carlos. Como elaborar projetos de pesquisa. 6. ed. São Paulo: Atlas, 2017. 173 p. ISBN 9788597012613.

IEMI (Inteligência de Mercado). Mercado, conjuntura atual e estimativas futuras Têxteis, Vestuário e Cameba. Dezembro 2020. Disponível em:

https://www.yumpu.com/pt/embed/view/c7LnvofUElyiHqQ5. Acesso em: 15 jan 2021

IFSC - Instituto Federal de Santa Catarina. Resolução nº 61/2016 CONSUP/IFSC.

Regulamenta as Atividades de Extensão no IFSC. Disponível em:

http://cs.ifsc.edu.br/portal/files/consup_resoluca061_2016_extensao.pdf Acesso em: 28 de fev. 2021

IFSC - Instituto Federal de Santa Catarina. Resolução CONSUP No 40, de 29 de agosto de 2016. Aprova as diretrizes para inclusão das atividades de extensão nos currículos dos cursos de graduação do IFSC e dá outras providências. Disponível em:

http://cs.ifsc.edu.br/portal/index.php?option=com_content\&view=section\&id=6\&layout=blog\& Itemid=21 Acesso em: 28 de fev. 2021

IFSC - Instituto Federal de Santa Catarina. Plano de Desenvolvimento Institucional (PDI) do IFSC 2020-2024. 2020. Disponível em: https://www.ifsc.edu.br/pdi-2020-2024 Acesso em: 28 de fev. 2021.

IFSC - Instituto Federal de Santa Catarina - Câmpus Araranguá. Ministério da Educação. PPC do curso superior de tecnologia em design de moda. 2014. Disponível em:

https://drive.google.com/drive/folders/OB6u-xoZB7RpudXNGdW1IS2dmYTQ. Acesso em: 12 jun. 2019.

SANTOS, Neri dos. Fundamentos teóricos de gestão do conhecimento [recurso eletrônico on-line]. Florianópolis: Pandion, 2020

TNSUL. Nova diretoria assume Núcleo de Moda Sul Catarinense. Disponível em: https://tnsul.com/2017/geral/nova-diretoria-assume-nucleo-de-moda-sul-catarinense/ Acesso em: 11 nov. 2021.

Recebido em: 11 de novembro de 2021. Aceito em: 12 de dezembro de 2021. Publicado em: 05 de janeiro de 2022. 